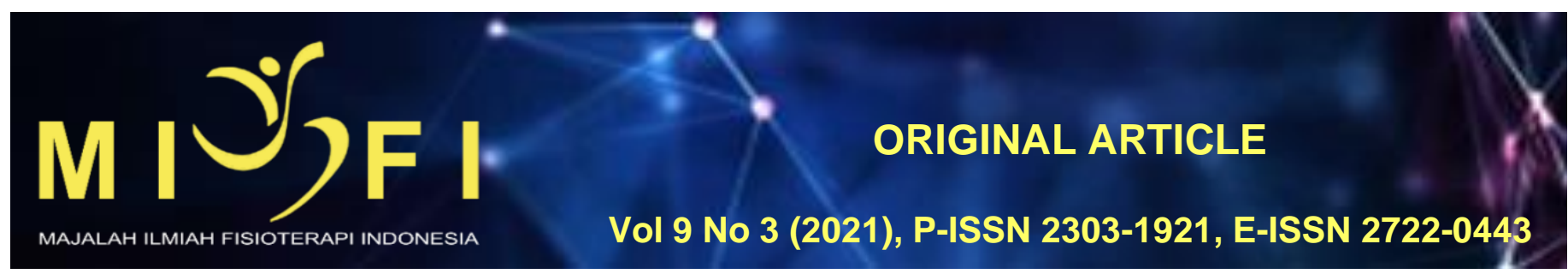

\title{
HUBUNGAN KOORDINASI MATA TANGAN DENGAN KEBERHASILAN MELAKUKAN FREE THROW PADA PEMAIN BASKET SMA DI DENPASAR
}

\author{
Putu Rama Adhityadharma', Made Widnyana², Anak Ayu Nyoman Trisna Narta Dewi ${ }^{3}$, \\ Ida Ayu Dewi Wiryanthini ${ }^{4}$ \\ ${ }^{1}$ Program Studi Sarjana Fisioterapi dan Profesi Fisioterapi, Fakultas Kedokteran, Universitas Udayana, Denpasar, Bali \\ ${ }^{2,3}$ Departemen Fisioterapi, Fakultas Kedokteran, Universitas Udayana, Denpasar, Bali \\ ${ }^{4}$ Departemen Biokimia, Fakultas Kedokteran, Universitas Udayana, Denpasar, Bali \\ ramaadhitya20@gmail.com
}

\begin{abstract}
ABSTRAK
Basket dimainkan oleh lima orang pemain dengan menggabungkan beberapa gerakan yang sangat komplek seperti koordinasi, kelincahan, ketepatan, dan kelentukan. Kemampuan koordinasi dalam permainan basket sangat diperlukan khususnya koordinasi mata tangan, karena inti permainan basket adalah memasukkan bola kedalam keranjang sebanyak-banyaknya. Koordinasi mata tangan berpengaruh dalam menentukan target kemudian memasukkan bola kedalam keranjang. Kesempatan penting seperti free throw juga sangat membutuhkan koordinasi mata tangan. Penelitian ini dillaksanakan untuk mengetahui pengaruh koordinasi mata tangan dengan kemampuan free throw. Penelitian ini merupakan penelitian observasional analitik dengan metode potong lintang, yang artinya dalam melaksanakan penelitian ini dilakukan observasi hanya satu kali dan juga mengukur variabel penelitian dilakukan saat pemeriksaan. Penelitian dilakukan di SMAN 3 Denpasar pada bulan Maret 2020. Pengambilan sampel dalam penelitian ini adalah non-probability sampling dengan metode purposive sampling yaitu peneliti memilih berdasarkan responden yang datang pada saat penelitian berlangsung dan memenuhi untuk kriteria inklusi dengan jumlah sampel sebanyak 47 sampel. Hasil uji chi-square menunjukkan adanya hubungan antara koordinasi mata tangan dengan kemampuan free throw dengan nilai $p=0,016(p<0,05)$ dengan nilai $r=0,48$ yang menyatakan adanya hubungan dengan kekuatan cukup dan searah. Koordinasi mata tangan memiliki hubungan dengan keampuan free throw dengan nilai $p=0,016$ dan memiliki kuat hubungan cukup dan searah dengan nilai $r=0,48$. Hubungan ini akibat korteks visual primer mengintegrasikan arah dan jarak dan efektor akan menyesuaikan dengan kekuatan lemparan sesuai jarak dan apa yang menjadi imput korteks sehinggan bisa dilakukan free throw.

Kata kunci: basket, koordinasi mata tangan, free throw
\end{abstract}

\section{THE CORRELATION BETWEEN EYE-HAND COORDINATION AND THE ABILITY TO DO FREE THROW IN HIGHSCHOOL BASKETBALL PLAYERS IN DENPASAR}

\section{ABSTRACT}

Basketball is a sport played by five peoples which combined complex movements such as coordination, agility, focus, and flexibility. The ability of coordination is essential in basketball, especially the eye-hand coordination. Eyehand coordination is playing such a big part during free throw. This research was conducted to see whether or not there is a correlation between eye-hand coordination and the ability to do free throw. This research was an observational analytic study using the cross-sectional method by collecting primary data on March 2020 from SMAN 3 Denpasar. Probability sampling was used with method of purposive sampling. The total of samples were 47. Result obtained showed there is correlation between eye-hand coordination and the ability to do free throw ( $p$ value $=0,016)(p<0,05)$ with $(r$ value $=0,48)$ which showed enough linear correlation. The primary visual cortex integrates the direction and distance and the effector will adjust the strength of the throw according to the distance and what the cortex imparts so that a free throw can be done. There was correlation between eye hand coordination and the ability to do free throw with the $p$ value $=0,016$ and there was enough and linear correlation between the two variable with $r$ value $=0,48$. This correlation is caused by the primary visual cortex integrates the direction and distance, and the effector will adjust the strength of the throw according to the distance, and what the cortex imparts so that a free throw can be done.

Keywords: basketball, eye-hand coordination, free throw

\section{PENDAHULUAN}

Basket merupakan olahraga yang dimainkan oleh lima orang pemain dengan cara memasukkan bola sebanyakbanyaknya ke dalam keranjang dan juga menahan tim lawan agar tidak dapat memasukkan bola ke daerah tim dengan waktu yang ditentukan. Basket merupakan olahraga yang sangat komplek menggabungkan gerakan seperti kelincahan, ketepatan, dan kelentukan. ${ }^{1}$

Setiap olahraga memiliki komponen biomotorik masing-masing. Secara garis besar ada dua faktor yang mempengaruhi penampilan seorang olahragawan. Pertama adalah health related factor dan yang kedua adalah skilled related factor. Olahraga basket harus ditunjang dengan baik oleh kedua faktor tersebut. Komponen biomotorik yang harus dimiliki oleh pemain basket adalah kecepatan (speed), daya ledak (power), kekuatan (strength), keseimbangan (balance), kelincahan (agility), ketepatan (accuracy), daya tahan (endurance), kelentukan (flexibility), dan koordinasi 
(coordination). Semua komponen ini menunjang keberhasilan dalam tim basket. Selain hal tersebut penguasaan teknik dalam bermain juga mempengaruhi keberhasilan dalam permainan basket. Pada basket sendiri memiliki teknik dasar berupa menggiring bola (dribble), olah kaki (pivot), menembak (shooting), lempar-tangkap (passing and catching), dan rebound. ${ }^{2}$

Semua teknik dasar memiliki fungsinya masing-masing tidak ada yang lebih baik maupun lemah karena basket merupakan permainan yang sangat dinamis. Mencetak angka pada bola basket harus dilakukan karena menembak (shooting) bola ke dalam ring lawan sebanyak-banyaknya untuk memenangkan permainan. Kemampuan shooting yang baik akan berbanding lurus dengan poin yang diciptakan oleh tim, dalam permainan sering pemain lawan melakukan pelanggaran terhadap pemain yang akan melakukan shooting sehingga wasit akan memberi hukuman dan yang dilanggar akan diberi kesempatan untuk melakukan free-throw dengan kesempatan memasukan bola sebanyak satu kali, dua kali, dan tiga kali ke keranjang sesuai dengan posisi pemain yang dilanggar. ${ }^{3}$

Free-throw merupakan tembakan ke udara mengarah ke keranjang lawan dengan kedua tangan untuk mencetak angka tanpa adanya gangguan pemain lawan. Free throw tidak bisa diwakilkan oleh pemain lain dalam pelaksanaannya. ${ }^{3}$ Setiap poin yang didapatkan melalui free throw adalah $20 \%$ dari total poin yang dihasilkan tim, dan pelanggaran sering dilakukan saat permaianan akan selesai sehingga kemungkinan tim untuk membalikkan keadaan melalui free throw sangat tinggi. ${ }^{4}$ Free-throw mampu membalikkan keadaan tim jika waktu permainan akan habis, tentu hal ini merupakan hal yang penting demi kemenangan tim, namun pada prakteknya free-throw tidak semudah yang dilihat. ${ }^{5}$ Banyak faktor-faktor yang mempengaruhi keberhasilan free-throw ada kemampuan fisik dan psikis dari atlet. ${ }^{2}$ Kemampuan psikis yang dimaksud adalah kemampuan atlet mengatur emosi, gejolak emosi yang terlalu tinggi karena rasa takut kemudian mempengaruhi permaianan. Kemampuan fisik yang sangat berpengaruh dalam melakukan free throw adalah koordinasi mata tangan. ${ }^{6}$

Koordinasi merupakan komponen biomotorik yang terdiri dari banyak gerakan yang kemudian disesuaikan menjadi satu gerakan yang harmonis dan berkaitan dengan keterampilan. Koordinasi mata-tangan merupakan skill memantulkan, memukul, atau melempar suatu objek ke suatu sasaran tertentu dan hal ini erat kaitannya dengan kemampuan untuk melemparkan bola basket ke dalam keranjang yaitu saat situasi free-throw. ${ }^{6}$

Koordinasi mata tangan adalah gerakan yang kompleks dari hubungan sistem mata dengan dengan manual motor sistem manusia. Mata mengarahkan gerakan seperti menggenggam, meraih, dan memanipulasi objek bergantung pada kemampuan untuk menganalisa keadaan lingkungan dan menghaluskan respon dari koordinasi motor pada tangan sehingga menghasilkan gerakan yang terkontrol, akurat dan cepat. ${ }^{7}$

Menurut Wardana koordinasi mata tangan sangat signifikan dalam keberhasilan free throw dan hal ini juga terjadi pada penelitian dari Kurniawan yang menyatakan keberhasilan free throw sangat dipengaruhi oleh koordinasi mata tangan. Hubungan koordinasi mata tangan ini memiliki peranan penting sehingga free throw dapat dilaksanakan dengan baik dan menjadi faktor yang mampu membalikkan keadaan skor dalam permainan. Diharapkan penelitian ini dapat menjadi pengembangan ilmu pengetahuan tentang koordinasi mata tangan yang baik dengan keberhasilan melakukan free throw pada pemain basket SMAN 3 Denpasar, dan mempermudah pelatih untuk evaluasi dan monitoring dalam konteks klinis maupun praktis. Berdasarkan uraian di atas maka peneliti ingin mengetahui hubungan koordinasi mata tangan dengan keberhasilan melakukan free throw.

\section{METODE}

Penelitian ini menggunakan rancangan penelitian observasional analitik dengan metode potong lintang, Penelitian ini memiliki dua variabel yaitu variabel bebas yang merupakan koordinasi mata tangan dengan variabel terikatnya adalah lemparan free throw. Penelitian dilakukan di lapangan basket SMAN 3 Denpasar dan dilkakukan pada bulan Maret 2020. Populasi target dalam peneltian ini adalah anggota ekstrakurikuler basket SMAN 3 Denpasar usia 15-18 tahun. Kriteria inklusi dalam penelitian ini adalah anggota ekstrakurikuler basket SMAN 3 Denpasar dengan rentan usia 15-18 tahun, vital sign baik dengan pemeriksaan dari fisioterapi, dan menyetujui dengan sukarela dan menandatangani informed consent. Kriteria eksklusi penelitian ini adalah subjek mengalami cedera musculoskletal pada ekstrimitas atas dan bawah, dan subjek mengalami gangguan koordinasi. Kriteria drop out pada penelitian ini adalah subjek tidak mengindahkan intruksi yang diberikan dan subjek mengundurkan diri.

Sampel yang dibutuhkan di penelitian ini sebanyak 47 subjek dengan teknik pengambilan sampel secara nonprobability sampling dengan metode purposive sampling. Sampel dalam penelitian inin melakukan tes koordinasi mata tangan terlebih dahulu kemudian dilanjutkan dengan tes lemparan free throw AAHPERD. Tes koordinasi mata tangan diambil dari buku Tes Pengukuran Olahraga dan dalam melakukan tes ini sampel melemparkan bola tenis ke dinding sasaran sebanyak 20 kali dengan interpretasi berdasarkan kategori baik sekali dengan skor diatas 18, baik dengan rentang skor 14-17, sedang dengan rentang 9-13, kurang dengan rentang skor 5-8 dan kurang sekali dengan skor dibawah 4. Jarak antara pelempar dengan dinding sasaran sepanjang 2,5 m dan subjek diberikan percobaan dengan alat tes agar mengerti dengan teknis tes. ${ }^{8}$ Lemparan free throw AAHPERD dalam pelaksanaanya sampel menembak bola kedalam ring di garis free throw sebanyak 20 kali dan diklasifikasikan berdasarkan kategori baik sekali dengan rentang skor 16-20, baik dengan rentang skor 12-15, sedang dengan rentang skor 8-11, kurang dengan rentang skor 4-7, dan kurang sekali dengan rentang skor 1-3. ${ }^{9}$

Penelitian ini bertujuan untuk mengetahui adanya hubungan antara koordinasi mata tangan dengan kemampuan melakukan free throw. Analisis bivariat Chi Square Test digunakan untuk menganalisis hubungan kedua variabel. Menganalis gambaran umum tentang presentase jenis kelamin, koordinasi mata tangan, lemparan free throw digunakan analisis multivariat. Penelitian ini telah disetujui oleh Komisi Etik Penelitian (KEP) FK. UNUD/RSUP Sanglah Denpasar dengan nomor ethical clearence 2020.01.1.0071. 
Karakteristik sampel penelitian dianalisa berdasarkan jenis kelamin, koordinasi mata tangan, dan kemampuan free throw dijabarkan pada tabel 1.

Tabel 1. Karakteristik Responden.

\begin{tabular}{lcc}
\hline \multicolumn{1}{c}{ Variabel } & Frekuensi(n) & Presentase(\%) \\
\hline Jenis Kelamin & 35 & 74,5 \\
L & 12 & 25,5 \\
P & & \\
Koordinasi Mata Tangan & 3 & 6,4 \\
Baik Sekali & 8 & 17 \\
Baik & 17 & 36,2 \\
Sedang & 11 & 23,4 \\
Kurang & 8 & 17 \\
Kurang Sekali & & \\
Kemampuan Free throw & 0 & 0 \\
Baik Sekali & 4 & 8,5 \\
Baik & 13 & 27,7 \\
Sedang & 17 & 36,2 \\
Kurang & 13 & 27,7 \\
Kurang Sekali &
\end{tabular}

Data yang diperoleh dari 67 sampel didapatkan sampel terbanyak untuk koordinasi mata tangan adalah kategori sedang dengan sebanyak 17 sampel dan Kemampuan free throw dengan kategori kurang sebanyak 17 sampel. Kelompok sampel terdiri dari 35 laki-laki dan 12 perempuan.

Tabel 2. Uji Chi-Square.

\begin{tabular}{|c|c|c|c|c|c|c|c|c|c|c|c|c|}
\hline \multicolumn{10}{|c|}{ Keberhasilan Melakukan Free Throw } & \multirow{2}{*}{\multicolumn{2}{|c|}{ Total }} & \multirow{3}{*}{ o } \\
\hline & & \multicolumn{2}{|c|}{ Kurang Sekali } & \multicolumn{2}{|c|}{ Kurang } & \multicolumn{2}{|c|}{ Sedang } & \multicolumn{2}{|c|}{ Baik } & & & \\
\hline & & $\mathrm{n}$ & $\%$ & $\mathrm{n}$ & $\%$ & $\mathrm{n}$ & $\%$ & $\mathrm{n}$ & $\%$ & $\mathrm{n}$ & $\%$ & \\
\hline & Kurang Sekali & 7 & 87.5 & 1 & 12.5 & 0 & 0 & 0 & 0 & 8 & 100 & \\
\hline & Kurang & 3 & 27.3 & 5 & 45.5 & 2 & 18.2 & 1 & 9.1 & 11 & 100 & \\
\hline $\mathrm{EHC}$ & Sedang & 2 & 11.8 & 6 & 35.3 & 8 & 47.1 & 1 & 5.9 & 17 & 100 & 016 \\
\hline & Baik & 1 & 12.5 & 3 & 37.5 & 3 & 37.5 & 1 & 12.5 & 8 & 100 & 010 \\
\hline & Baik Sekali & 0 & 0 & 2 & 66.7 & 0 & 0 & 1 & 33.3 & 3 & 100 & \\
\hline & Total & 13 & 27.7 & 17 & 36.2 & 13 & 27.7 & 4 & 8.5 & 47 & 100 & \\
\hline
\end{tabular}

Berdasarkan tabel uji statistik chi-square dengan nilai asymptotic significance (2-sided) menunjukkan nilai $\mathrm{p}$ yang diperoleh sebesar 0,016, maka Hipotesis 0 ditolak dan Hipotesis a diterima, artinya ada hubungan antaran koordinasi mata tangan dengan keberhasilan melakukan free throw pada siswa SMAN 3 Denpasar.

Hasil uji kuat hubungan antara koordinasi mata tangan dengan kemampuan free throw dapat dilihat di tabel 3.

Tabel 3. Uji Spearman's rho

\begin{tabular}{cc}
\hline Korelasi Variabel & Reabilitas (R) \\
\hline Koordinasi Mata Tangan dengan Kemampuan free throw & 0,480 \\
\hline
\end{tabular}

Data uji Spearman's rho diperoleh nilai $r$ adalah 0,480 yang berarti ada hubungan searah positif dengan kuat hubungan yang cukup antara koordinasi mata tangan dengan keberhasilan melakukan free throw.

\section{DISKUSI}

Hasil penenlitian menunjukkan bahwa peserta paling banyak merupakan siswa laki-laki sebanyak 35 orang, diikuti dengan siswa perempuan sebanyak 12 orang. Total peserta dalam penelitian ini sebanyak 47 orang. Dilihat dari distribusi data koordinasi mata tangan dapat dilihat bahwa sampel dengan kategori sedang memiliki jumlah peserta terbanyak yaitu dengan 17 siswa, kategori kurang dengan 11 siswa, kategori baik memiliki jumlah 8 siswa begitu pula dengan kategori kurang dengan jumlah 8 siswa, dan kategori baik sekali dengan jumlah peserta penelitian sebanyak 3 orang. Ditinjau dari kemampuan free throw peserta penelitian yang berada di kategori kurang paling banyak yaitu sebanyak 17 siswa, kategori sedang memiliki jumlah 13 siswa begitupula dengan kategori kurang sekali yang berjumlah 13 siswa juga, kategori baik dengan jumlah peserta sebanyak 4 orang, dan tidak ada peserta yang memiliki kemampuan free throw dengan kategori baik sekali. Keberhasilan melakukan free throw tidak terlepas dari akurasi atau ketepatan dari tembakan. Memasukkan bola ke dalam keranjang membutuhkan akurasi yang baik. Akurasi adalah ketepatan dalam pengukuran sesuatu sehingga dalam melakukan free throw pengukuran yang tepat akan menghasilkan hal yang diinginkan. Pemain yang memiliki akurasi yang baik mampu melakukan gerakan free throw yang baik secara berulangulang. ${ }^{9}$ Gerakan free throw ini membutuhkan koordinasi mata tangan yang baik untuk memasukkan bola ke dalam ring. ${ }^{7}$

Koordinasi adalah kemampuan untuk dapat menguasai gerakan di berbagai situasi dengan baik dan tepat. Koordinasi merupakan dasar bagi seseorang untuk belajar melatih sensori motoriknya. Koordinasi juga adalah kemampuan dari seseorang mengintegrasi bermacam gerakan yang berbeda menjadi suatu kesatuan pola gerakan yang efektif. ${ }^{11}$ Koordinasi mata tangan sangat besar pengaruhnya dalam gerak olahraga yang melibatkan fungsi tangan dan pengamatan suatu obyek. 
Koordinasi merupakan hubungan yang saling berpengaruh dan harmonis di dalam kelompok otot yang mempengaruhi tingkat keterampilan seorang atlet. Koordinasi mata tangan bergantung pada mata untuk membantu dalam mengarahkan untuk memasukkan benda dengan mengorientasikan gerakan lengan, dan menggunakan alat, dan meliputi juga gerakan yang berkaitan dengan kegiatan fungsional laiinnya. ${ }^{12}$ Keharmonisan kerja otot dan mata dalam mengintegrasi aktivitas gerak adalah koordinasi mata tangan. Mata sebagai indra penglihatan untuk mengintegrasi rangsangan yang diterima dan tangan sebagai penggerak utama dalam untuk melakukan gerakan sesuai dengan rangsangan dari mata. ${ }^{2}$

Koordinasi mata tangan sangat diperukan dalam permainan basket karena sebagaian besar permainan basket menggunakan mata dan tangan untuk bermain. Kemampuan-kemampuan dasar harus dimiliki pemain basket khususnya dalam melakukan free throw karena hal ini merupakan kesempatan untuk menambah angka dan tidak dapat diganti dengan pemain lain.

Berdasarkan hasil pengujian data chi-square dengan nilai asymptotic significance (2-sided) pada jumlah data sebanyak 47 sampel, ditemukan nilai $p$ sebesar 0,016 yang lebih kecil dari nilai standar $0,05(p<0,05)$. Hal ini menunjukkan ada hubungan koordinasi mata tangan dengan kemampuan free throw pada siswa pemain basket SMAN 3 Denpasar. Kuat hubungan koordinasi mata tangan dengan kemampuan free throw dengan nilai $r$ sebesar 0,48 dengan interpretasi korelasi cukup $(0,26-0,50)$ dan arah hubungan searah positif karena nilai $r$ positif.

Sejalan dengan penelitian Wardana pada tahun 2017 yang mengatakan bahwa pemain basket yang memiliki koordinasi mata tangan yang tinggi memiliki kemampuan free throw yang baik dengan nilai $p$ sebesar $0,035(p<0,05)$ dengan 20 sampel. Penenlitian ini menggunakan tes AAHPERD untuk pengukuran free throw dan catch tennis ball dari Kirkendall untuk pengukuran koordinasi mata tangan. Pada penelitian ini juga dikatakan pelatihan koordinasi mata tangan secara direct akan meningkatkan kemampuan free throw pada pemain basket dibandingkan dengan metode latihan yang bersifat indirect. Wardana mengatakan bahwa pemain basket yang memiliki koordinasi mata tangan yang baik mampu melaksanakan pembelajran dengan benar sesuai dengan keselarasan gerak dengan tingkat energi yang dibutuhkan untuk melaksanakan gerak yang diperintahkan. ${ }^{6}$

Penelitian dari Kurniawan pada tahun 2016 menyatakan ada hubungan yang signifikan antara koordinasi mata tangan dengan kemampuan free throw dikarenakan thitung $>$ tabel $(6,781>1,998)$. Penelitian ini menggunakan 12 sampel pemain basket putra di Unnes. Penelitian ini menghitung beberapa faktor lainnya yang dapat memepengaruhi dari keterampilan free throw seperti kekukatan otot lengan, kekuatan otot tungkai, fleksibilitas pergelangan tangan, dan fleksibilitas togok. ${ }^{9}$

Visual input diproses oleh region kortikal yang biasanya dikenal sebagai korteks visual primer (V1) atau juga sering disebut dengan korteks striate. Letak korteks visual primer (V1) yaitu dibagian posterior lobus occipital. Korteks ini memiliki fungsi untuk pemrosesan primitif seperti kontur benda padat, kemudian dari hasil proses ini menuju region kortikal yaitu extrastriate cortex yang berdekatan dengan korteks visual primer yaitu di region kortikal. Representasi topografi bidang visual kontralateral merupakan prinsip dasar dari pengorganisasian area visual ini. Proses ini bercabang menjadi dua alur yaitu apa dan dimana. Jalur apa memproses dari identitas objek serta visual sedangkan jalur dimaan memproses dari perhatian spasial dan gerakan. Memproses input dari visual untuk gerakan yang bersifat prediktif dan antisipatif melibatkan juga jalur dorsal dan hal ini termasuk dari koordinasi mata dan tangan. Kedua aliran ini, baik ventral maupun dorsal dianggap membantu dari koordinasi mata tangan. ${ }^{7}$

Menempatkan jari/tangan atau efektor manual pada posisi yang ditentukan oleh otak merupakan tujuan akhir dari koordinasi mata tangan untuk melaksanakan program motorik. Korteks motorik primer (M1), korteks suplementer, dan premotor adalah jaringan neuroanatomi yang bertanggung jawab langsung atas gerakan lengan dan tangan. Gerakan tangan dihasilkan dari korteks motorik primer, hal ini karena korteks motoris primer memiliki tanggung jawab untuk meyampaikan informasi turun menuju traktus kortikospinalis. Korteks premotor memiliki fungsi dalam perencanaan gerakan yang bersifat antisipatif, gerakan tangan dengan input spasial, dan juga untuk pemrosesan input sensorik untuk membantu dari gerakan tangan. Korteks motorik suplementer memiliki fungsi sebagai perencanaan gerakan manual. ${ }^{7}$

Korteks posterior parietal (PPC), korteks somatosensori, cerebellum, ganglia basalis, dan juga jaringan kortikal dilengkapi oleh jaringan yang lebih besar dibandingkan daerah kortikal dan subkortikal. Informasi visual dan input dari korteks somatosensori diterjemahkan oleh korteks posterior parietal sebagai wilayah asosiatif. Informasi ini kemudian diubah menjadi perintah motorik. Gerakan tangan biasanya didahului oleh gerakan mata karena mata akan mengarakan pandangan kearah target sebelum terjadinya gerakan tangan. ${ }^{7}$

Koordinasi mata tangan juga mempengaruhi dari hasil standing throw shoot dari pemain basket. Koordinasi mata tangan mempunyai peran dalam permainan bola yang menggunakan tangan. Pemain yang menembakkan bola menggunakan tangan harus memperhatikan gerakan, ayunan tangan dan waktu tembakan secara harmonis, sehingga pemain harus mempertimbangkan gerakan secara cepat dan presisi kearah target. ${ }^{10}$

\section{SIMPULAN}

Berdasarkan pembahasan dapat disimpulkan bahwa hubungan antara koordinasi mata tangan dengan keberhasilan melakukan free throw pada pemain basket SMA di Denpasar dengan kuat hubungan yang cukup. Korteks visual primer mengintegrasikan arah dan jarak dan efektor akan menyesuaikan dengan kekuatan lemparan sesuai jarak dan apa yang menjadi imput korteks sehinggan bisa dilakukan free throw

\section{DAFTAR PUSTAKA}

1. Ricardo, A., 2014. Kontribusi Kekuatan Otot Lengan Danrentang Lengan Terhadap Keterampilan Jump Shoot pada Permainan Bola Basket pada Siswa dan Siswi Kelas VIII Smp Negeri 17 Kota Bengkulu. Skripsi. Bengkulu: Universitas Bengkulu Universitas Bengkulu. 
2. Prasetya, S.D., 2011. Perbedaan Pengaruh Modifikasi Peralatan dan Koordinasi Mata Tangan Terhadap Kemampuan Tembakan Bebas Bola Basket pada Siswa Putra Kelas VIII SMP Negeri 25 Surakarta. Skripsi. Surakarta: Universitas Sebelas Maret Universitas Sebelas Maret.

3. PERBASI, 2010. Peraturan Resmi Bola Basket. PERBASI.

4. Uchida, Y., 2014. Prediction of shot success for basketball free throws:Visual search strategy. European Journal of Sport Science, 14(5), pp.426-32.

5. Iskandar, 2014. Hubungan Koordinasi Mata-tangan dengan Servis Atas Bola Voli Mahasiswa Putra Penjaskes IKIP-PGRI Pontianak. Jurnal Pendidikan Olah Raga, 3(2).

6. Wardana, P., 2017. Pengaruh Pendekatan Pembelajaran dan Koordinasi Mata-Tangan Terhadap Hasil Free Throw. Skripsi. Surakarta: Universitas Sebelas Maret Fakultas Pascasarjana IImu Keolahragaan.

7. Rizzo, J.-R., 2017. The Intersection between Ocular and Manual Motor Control: Eye-Hand Coordination in Acquired Brain Injury. Frontiers in Neurology, 8, p.227.

8. Fenanlampir, A. \& Faruq, M.M., 2015. Tes dan Pengukuran dalam Olahraga. Yogyakarta: CV. Andi Offset.

9. Kurniawan, A.C., 2016. Prediksi Keterampilan Free Throw pada Bola Basket Ditinjau dari Kemampuan Fisik ( Studi Korelasional Power Otot Lengan, Power Otot Tungkai, Fleksibilitas Pergelangan Tangan, Fleksibilitas Togok, Koordinasi Mata Tangan pada Atlet Bola Basket Putra Tingkat. Skripsi. Surakarta: Universitas Sebelas Maret Universitas Sebelas Maret.

10. Sunawa, M.K., Rustiadi, T. \& Soekardi, 2018. The Contribution of Hand-Eye Coordination, Muscle Arm Strength. Journal of Physical Education and Sports, 7(2), pp.141-51. 